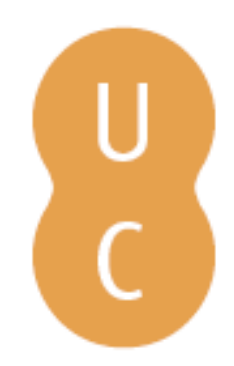

\title{
pommalina
}

\section{Díaita: estilo de vida y alteridad en la Ciropedia de Jenofonte}

Autor(es): $\quad$ Sierra Martín, César

Publicado por: Imprensa da Universidade de Coimbra

URL

persistente: URI:http://hdl.handle.net/10316.2/39644

DOI: $\quad$ DOI:https://doi.org/10.14195/978-989-26-1191-4_15

Accessed : $\quad$ 26-Apr-2023 15:37:00

A navegação consulta e descarregamento dos títulos inseridos nas Bibliotecas Digitais UC Digitalis, UC Pombalina e UC Impactum, pressupõem a aceitação plena e sem reservas dos Termos e Condições de Uso destas Bibliotecas Digitais, disponíveis em https://digitalis.uc.pt/pt-pt/termos.

Conforme exposto nos referidos Termos e Condições de Uso, o descarregamento de títulos de acesso restrito requer uma licença válida de autorização devendo o utilizador aceder ao(s) documento(s) a partir de um endereço de IP da instituição detentora da supramencionada licença.

Ao utilizador é apenas permitido o descarregamento para uso pessoal, pelo que o emprego do(s) título(s) descarregado(s) para outro fim, designadamente comercial, carece de autorização do respetivo autor ou editor da obra.

Na medida em que todas as obras da UC Digitalis se encontram protegidas pelo Código do Direito de Autor e Direitos Conexos e demais legislação aplicável, toda a cópia, parcial ou total, deste documento, nos casos em que é legalmente admitida, deverá conter ou fazer-se acompanhar por este aviso.

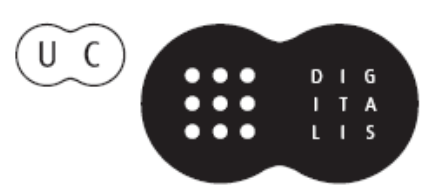




\title{
DÍAITA: ESTILO DE VIDA Y ALTERIDAD EN \\ LA CIROPEDIA DE JenOFOnTE \\ Diaita: lifestyle and alterity in Xenophon's Cyropaedia
}

\author{
César Sierra Martín \\ Universitat Oberta de Catalunya, Estudis d'arts i humanitats \\ HICOAN-2014SGR1111
}

\begin{abstract}
Resumen: el trabajo parte de la definición de conceptos y principios generales de la dietética clásica, trabajando términos como phýsis, dýnamis y díaita en algunos escritos de la colección hipocrática. Posteriormente se mide la influencia de éstos en la confección de un ideal de virtud humana en la Ciropedia de Jenofonte.
\end{abstract}

Palabras clave: dietética clásica, virtud humana, medicina hipocrática, Jenofonte.

AвSTRACT: the aim of the current work is to analyze concepts and general principles of the Classical diet by studying terms such as physis, dynamis and diaita from the Hippocratic collection. Moreover, it accounts for the influence of these terms on the construction of a human virtue model as shown in the Xenophon's Cyropaedia. KeYwords: classical diet, human virtue, Hippocratic medicine, Xenophon.

Exponemos los resultados de un trabajo que se enmarca en un proyecto personal más amplio, cuyo objetivo es analizar la recepción en Jenofonte de ideas, conceptos y modelos sobre alimentación y dietética. A grandes rasgos, este proyecto parte de un mapa conceptual sobre la perspectiva médica de la dietética clásica y analiza cómo dichos conceptos son permeables y visibles en la obra de Jenofonte ${ }^{1}$. Como punto de partida definiremos los rasgos generales de la dietética médica recogidos en los tratados hipocráticos, atendiendo especialmente a términos como phýsis, dýnamis y diaita; posteriormente me centraré en la recepción y aplicación de los mismos en la Ciropedia.

\section{I}

La colección hipocrática es un conglomerado de escritos de diferente autoría y época que comprende desde el siglo V a.C. al II d.C. ${ }^{2}$ No se trata entonces de una obra homogénea sino de una compilación artificial que recoge

\footnotetext{
${ }^{1}$ Agradezco los comentarios que sobre este trabajo ha realizado la profesora Inmaculada Rodríguez; por supuesto lo errores que pueda contener son de mi autoría.

Los primeros resultados pueden consultarse en Sierra 2013a y 2013b.

${ }^{2}$ López Férez 1986: 159-161.
} 
las impresiones de diferentes personas (no siempre médicos) en diferentes momentos sobre los temas más diversos y todo ello bajo la supuesta rúbrica del prestigioso Hipócrates de $\mathrm{Cos}^{3}$. Por este motivo resulta complicado extraer ideas universales que puedan calificarse de 'hipocráticas', ya que, en general, encontramos multitud de opiniones sobre una misma cuestión ${ }^{4}$. La dietética no es una excepción, pese a ser una materia que podríamos calificar de transversal dentro de los escritos hipocráticos. Entonces, ¿cómo ubicarnos en esta dietética médica? Uno de los tratados más extensos y famosos, Sobre la dieta $(=\text { Vict. })^{5}$, sugiere que el tratadista sobre dietética debe conocer lo siguiente:

Afirmo que quien pretende componer acertadamente un escrito sobre la dieta bumana debe, antes que nada, reconocer y discernir la naturaleza del hombre en general; conocer de qué partes está compuesto desde su origen y distinguir de qué elementos está dominado. Pues si no reconoce la composición fundamental, será incapaz de conocer lo que de ella se deriva. Y si no discierne qué es lo dominante en el cuerpo, no será capaz de procurarle lo conveniente al ser humano. Por tanto, eso debe conocerlo el autor de tal escrito y, juntamente con ello, la cualidad de todos los alimentos y las bebidas con las que nos mantenemos, qué propiedades tiene cada uno, tanto si proviene de su misma naturaleza, como si es debida a la ocasión forzada y a la técnica del hombre.

Vict. $2.1^{6}$

En el pasaje anterior se coligen los dos principios generales de la dietética médica: 1) conocer y reconocer (gnônai kai diagnônai) cada naturaleza

${ }^{3}$ El principal editor y traductor moderno del corpus hipocrático, Émile Littré (1801-1881), sugirió que la primera compilación de los escritos hipocráticos se produjo en la Alejandría del III a.C. y que hasta entonces los tratados circulaban por separado. En época de Littré las doctrinas atribuidas a Hipócrates, el hipocratismo, todavía tenían vigencia y el traductor otorgó cierta verosimilitud a la cuestión de la autoría de Hipócrates. Bien es cierto que la vinculación de los tratados con el propio Hipócrates, la denominada 'cuestión hipocrática', es un asunto que parte de la Antigüedad; como mínimo desde Erotiano y Galeno que escribieron sobre las genuinas o falsas obras de Hipócrates. En efecto, no todos los escritos del corpus pueden atribuirse a Hipócrates por motivos cronológicos pero, según creo, el debate no surge únicamente para distinguir al autor/es de cada escrito sino para dar respuesta a la evidente heterogeneidad de la colección hipocrática. Al abrigo de este problema también se han identificado varias líneas o escuelas médicas dentro de los escritos hipocráticos (Cnido y Cos, principalmente) pero resulta complicado dilucidar con nitidez y coherencia la composición interna del corpus. En las últimas décadas se ha escrito mucho sobre este interesante asunto, como así se observa en la excepcional síntesis de Smith 2002: 31-44.

${ }^{4}$ López Férez 1986: 62-63; Jouanna 1999: 56 ss.

${ }^{5}$ Datado en el último tercio del siglo V a.C. (v. Joly 2003: 44-45); El escrito se divide en cuatro libros que, a su vez, se inspiran en diferentes corrientes de pensamiento, como bien ha señalado Wilkins 2005. Nos centraremos más en este escrito por ser anterior a Jenofonte.

${ }^{6}$ En adelante seguimos la traducción de García Gual 2000. 
humana; 2) conocer la cualidad (dýnamis) de todos los alimentos y bebidas que son nuestro sustento.

Sobre el primer punto podemos extraer una idea que posee importantes connotaciones en materia de alteridad: los seres humanos no son iguales entre sí, tienen distinta naturaleza (phýsis) lo cual era percibido y asimilado por el médico. Por ejemplo, para tener una idea clara de cuál era la naturaleza del paciente era necesario tener presente factores como la edad, el género, la condición social y la procedencia. En resumen, no es lo mismo un joven que un adulto, un hombre que una mujer, un esclavo que un libre, un extranjero o un griego ${ }^{7} .$. Ciertamente, la percepción de la diversidad humana en la medicina tomó especial relevancia en el famoso escrito Aires, aguas y lugares (=Aër.) donde, además de todo lo anterior, se introduce en la ecuación el factor climatológico como reflexión etiológica de la alteridad ${ }^{8}$. El escrito destaca como concepto principal que el clima no es igual en todas partes y, en consecuencia, la naturaleza de los seres vivos varía: regiones cálidas producen un tipo determinado de flora y fauna que contrasta con la de regiones frías $y$, a su vez, este factor influye en la naturaleza de los seres humanos que allí habitaban'. Desde nuestro punto de vista, este razonamiento conduce a la generación de modelos ecológicos y humanos con evidentes implicaciones en materia de alteridad: el griego y el asiático no poseen la misma naturaleza (Aër. 16); todo lo cual se une a otros apriorismos de la época que no tienen que ver con la teoría climática: el libre y el esclavo no son iguales por naturaleza ${ }^{10}$.

Igualmente, dentro de un mismo clima, las variaciones de estación, la orientación de las ciudades, la calidad de las aguas o la exposición a determinados vientos son factores todos ellos que inciden y alteran la composición interna de las personas (Aër. 2). Se puede decir, de acuerdo con esta teoría

${ }^{7}$ Lo anterior forma parte de la condición del paciente (la katástasis) que depende de multitud de factores internos y externos, que el médico debe averiguar y definir antes de iniciar el diagnóstico. Sobre la katástasis en sentido médico aún me parece excelente el análisis de Pedro Laín (Laín Entralgo 1970: 67 ss.)

${ }^{8}$ Datado alrededor del último cuarto del siglo $\mathrm{V}$ a.C., existe una conocida controversia sobre la unidad de autor y obra (Jouanna 1996: 81-82).

${ }^{9}$ Influye también en las características naturales y psicológicas de las personas. El tema ha sido muy trabajado, por lo que es preferible limitar las citas de fuentes primarias y secundarias en pos de una lectura más fluida. De cualquier manera, sobre este tema véase Jouanna 1996: 57-71.

${ }^{10} \mathrm{El}$ autor de Epidemias recoge multitud de historias clínicas que reflejan su labor en diferentes ciudades. Resulta sintomático del argumento que presento el hecho de que en no pocas ocasiones se anote la condición social del paciente (libre/esclavo, rico/pobre) y la procedencia en caso de ser extranjero (bárbaro). Pienso que no es un apunte sociológico sino que forma parte de la condición médica del paciente junto a la edad, el género y el estilo de vida, entre otras peculiaridades (Sierra, en prensa). Tomando como axioma la idea según la cual los seres humanos poseen distinta naturaleza se justificaron condiciones sociales y jurídicas como la esclavitud, que tendrá una amplia aceptación y recorrido en la Antigüedad desde Aristóteles (Pol. 1253a-1254a; 1259 b 13; véase Paiaro 2012: 157-159). 
climática, que la naturaleza humana sufría cambios diariamente, lo cual debía tener muy presente el médico ${ }^{11}$. Que desde el exterior se pueda alterar la naturaleza del ser humano es otra idea transversal dentro de la medicina pragmática. No obstante, ¿qué entendían los médicos 'hipocráticos' por naturaleza humana? Nuevamente no hay una única teoría. Para comenzar, el pensamiento médico entendía el cuerpo humano según una combinación de cualidades opuestas (enantiosis) en equilibrio (isonomia) ${ }^{12}$. Bajo este esquema, pueden distinguirse hasta tres concepciones de la phýsis en la medicina hipocrática: la humoral, que seguía la teoría de los cuatro humores; la elemental, seguidora de la doctrina de los cuatro elementos de Empédocles (aire, agua, tierra y fuego), y la dinámica, centrada en cuatro cualidades contrapuestas (caliente, frío, seco y húmedo) ${ }^{13}$. El esquema anterior estaba sujeto de nuevo a interpretaciones, por ejemplo, algún escrito sigue la teoría humoral, según una concepción binaria de la misma (bilis/sangre o sangre/pituita; Flat. 6), y otros la cuaternaria (sangre, pituita, bilis amarilla, bilis negra; Nat.Hom. 4) o bien una combinada (sangre, flema, bilis, agua; Morb. 4) ${ }^{14}$. Además, hay que tener presente la trayectoria cronológica de estas teorías fisiológicas en conexión con sus respectivos fundamentos filosóficos. En realidad, el panorama es muy extenso y complejo como para resumirlo aquí aunque la idea radica en que estos pares de fuerzas opuestas dominaban el cuerpo humano ${ }^{15}$.

En cuanto al segundo punto, la idea de cualidad (dýnamis) de los alimentos es esencial para dibujar un esquema general de la dietética médica. Según Vict. 2, era de vital importancia para el médico conocer las propiedades de la comida y la bebida; pero más aún, prever las consecuencias de su ingesta en el organismo teniendo presente la variabilidad de la naturaleza humana. Como concepto general, la medicina pragmática entendía que los alimentos poseían una potencia o cualidad característica que, a su vez, potenciaba una cualidad afín en el interior del cuerpo humano. Así, un mismo alimento tendrá efectos distintos en cada individuo. Esto es especialmente palmario en el escrito Sobre el alimento $(=\text { Alim. })^{16}$, al igual que en el segundo libro de Sobre la

${ }^{11}$ Bien observado en Edelstein 1987a: 304.

${ }^{12}$ Planteamiento teórico que parte de Alcmeón de Crotona en el s. VI a.C. (v. Laín-Entralgo 1970: 33-34 ; Nutton 2004: 47-48); la proximidad de este concepto con el vocabulario político es interesante en cuanto asocia metafóricamente el cuerpo humano con el cuerpo cívico y, por ende, el médico con el líder político (Sierra 2014)

${ }^{13}$ Laín Entralgo 1982: 14.

${ }^{14}$ Para ampliar este tema destaco el trabajo de Thivel 1990 y, recientemente, Bartos 2015: 113 ss. en relación al caso concreto de Vict. 4, que sigue una teoría elemental binaria.

${ }^{15}$ Además, en un campo muy relacionado con la fisiología como es la anatomía vemos que la colección hipocrática muestra un conocimiento precario pues no fue hasta Aristóteles cuando los griegos comenzaron a utilizar las disecciones (en animales) para describir e investigar las funciones de los órganos internos. Sobre este asunto véase Lloyd 1991 y Craik 2006: 159.

${ }^{16}$ La datación de esta escrito hipocrático es un asunto complejo de dilucidar aunque parece 
dieta, donde se recoge un listado de alimentos y sus propiedades. El problema surge cuando se quiere concretar en el corpus hipocrático qué cualidades o propiedades tienen los alimentos (sólidos o líquidos), presentadas de nuevo en pares de opuestos (enantiosis): seco/húmedo, dulce/amargo, caliente/frío, laxante/astringente, etc. Estas cualidades se establecían según la experiencia y observación del especialista por lo que no encontramos uniformidad alguna. Del mismo modo, aquellas cualidades afines que los alimentos potencian en el interior del cuerpo humano también constituyen un elemento de análisis problemático debido a la comentada disparidad de opiniones en relación a la naturaleza humana ${ }^{17}$. Ciertamente, el fundamento filosófico sobre el que descansa la dietética médica es complejo, heterogéneo y dependía del dietista, quien debía conocer la dýnamis del alimento y administrarlo para corregir algún desequilibrio interno (enfermedad), teniendo presente la naturaleza del problema y del paciente, así como su estilo de vida (díaita) ${ }^{18}$. Al inicio de Aër. hay una buena glosa de lo que significa desde el punto de vista médico tanto la dýnamis de los alimentos como la díata de las personas:

Después, ha de conocer [el médico] los vientos, calientes y frios, especialmente los que son comunes a todos los hombres, $y$, además, los típicos de cada país. También debe ocuparse de las propiedades de las aguas, pues, tal como difieren en la boca y por su peso, asi también es muy distinta la propiedad de cada una. (Aër. 1.2) [...] Además, hay que enterarse de qué tipo de vida gozan los habitantes: si son bebedores, toman dos comidas al día y no soportan la fatiga, o si aman el ejercicio físico y el trabajo, comen bien y beben poco (Aër. 1.5) ${ }^{19}$.

En este pasaje la dýnamis no se reduce a los alimentos sino que se extiende a un amplio abanico de situaciones. Los vientos o el sol presentan una dýnamis particular e inciden sobre la naturaleza de animales y plantas; también las aguas tienen distinta calidad y cualidades y, en el caso de los seres humanos, se añade el estilo de vida como otro factor externo que altera el delicado equilibrio que conforma el organismo. Así pues, se aprecia la amplitud semántica del término dýnamis lo cual es difícil de trasladar a idiomas modernos, razón por la que Jacques Jouanna lo ha calificado de 'intraducible' a la hora de abordar este mismo pasaje ${ }^{20}$.

imponerse una datación tardía (s. I d.C.) tras detectarse influencias de la escuela pneumática. Véase en general Rodríguez Alfageme 1997: 242-244 y Sierra 2013a: 469 n28.

${ }^{17}$ Las discrepancias entre los médicos en esta materia son advertidas en Acut. 6.

${ }^{18}$ En un precedente a este trabajo realicé un análisis a nivel conceptual del término díaita, con la debida bibliografía (Sierra 2013a: 463-468). En esta ocasión presentaré la cuestión de forma sintética.

${ }^{19}$ Seguimos la traducción de López Férez 2000.

${ }^{20}$ Siendo 'cualidad' o 'propiedad'las traducciones más cercanas (Jouanna 2012c: 159). 
Poco después de analizar la importancia de la dýnamis de las aguas, el autor/es de $A \ddot{e}$. remite al estudio del estilo de vida de los habitantes de una región para conocer su predisposición a las enfermedades. El estilo de vida (díaita) es un concepto basto que se extiende a las costumbres diarias entre las que sobresalen dos: la alimentación y la actividad física, ambas moduladas en función de la cantidad, la variedad y la frecuencia ${ }^{21}$. Ambas son los pilares básicos de la díaita bajo la idea de que la combinación de ambos influía en el equilibrio que definía la salud humana. La consecuencia de este principio es asumir que las costumbres (nómoi) repercutían en la salud ${ }^{22}$. De este modo, el médico podía identificar un problema de salud en una mala alimentación o, también, en un estilo de vida desordenado, lo cual está de nuevo en íntima relación con la phýsis de cada persona ${ }^{23}$. Tampoco se trataba de definir las propiedades de los alimentos y administrarlos sin más, junto a cualquier tipo de actividad física pues: Es importante armonizar con éxito la cantidad a la potencia [dýnamis] (Alim. 35) 24. Para un dietista lo menos relevante era el deleite en la comida o el ornamento culinario sino calcular la cantidad adecuada de alimento, saber su dýnamis e investigar el mayor número posible de elementos externos que alteren la phýsis del sujeto. El alimento podía ser muy sencillo pero debía ser adecuado a la circunstancia de cada persona. A su vez, cada naturaleza puede soportar una cantidad y frecuencia determinada de ejercicios en función de la edad, el sexo, la constitución física, la alimentación, la estación del año, el clima... Quizás un factor que ayudó a socializar y popularizar la noción del equilibrio entre alimentos y ejercicio se recoja en el escrito Sobre la dieta en las enfermedades agudas (= Acut.) donde se especifica que: No sólo ayuda a la curación de los enfermos; sirve también para que los sanos conserven la salud e incluso incrementen sus fuerzas (Acut. 9.1). En efecto, existía un díaita propia de enfermos y otra higiénica orientada a mantener la salud ${ }^{25}$. De acuerdo con Ludwig Edelstein, esta dietética higiénica, tan preocupada por la correcta combinación entre alimentos y ejercicios, terminó por constituir una diferenciación social desde el mismo momento que el hombre debe ajustar su modo de vida a estos preceptos ${ }^{26}$. No es para menos, puesto que sólo un reducido grupo social disponía libremente de su persona y de su tiempo para

${ }^{21} \mathrm{El}$ concepto díaita no se utiliza igual en toda la colección hipocrática, en algunos casos se circunscribe a la alimentación pero, en general, hace referencia al estilo de vida. Véase Jouanna 2012a: 139.

${ }^{22}$ Muy bien advertido por Laín Entralgo 1970: 319.

${ }^{23} \mathrm{El}$ conjunto de factores externos que un médico debía tener presente era tal que el propio autor/es de Aër. 2 no aspiraba a controlarlos todos sino que recomendaba estudiar los más posibles para adelantarse a la aparición de las enfermedades.

${ }^{24}$ También en Vict. 9. 3; Jouanna 2012a: 147.

${ }^{25}$ Una separación definitoria de la dietética para Pedro Laín (Laín Entralgo 1970: 318).

${ }^{26}$ Edelstein 1987a: 306. 
dedicarlo al cuerpo. Este argumento no es una opinión de la crítica moderna, como así se vislumbra ya en los propios escritos médicos:

En primer lugar, pues, en interés de la mayoría de la gente escribiré con qué medios pueden ayudarse quienes toman las comidas y bebidas ocasionales, entre trabajos obligados, viajes forzados por sus necesidades, y travesías por mar en busca de sustento, expuestos al sol en contra de los conveniente, sometidos al frio al margen de lo útil, y recurriendo a un régimen de vida de lo más inestable. Para éstos, pues, de acuerdo con las circunstancias, resulta conveniente adoptar la dieta que vamos a exponer.

Vict. 68.1

Un pasaje muy elocuente acerca de las implicaciones de la dietética higiénica en la diferenciación social. Ahora bien, ¿quien tenía tiempo y medios para mantener una dieta variada, realizar paseos, ir a la palestra o tomar baños? Para la mayoría existía otra díaita que no sólo era más adecuada a sus circunstancias, como sugiere el escrito, sino que terminó por definir a unos y a otros. Asimismo Platón ( $R$. 406d) detalla, no sin ironía, la incompatibilidad de este tipo de medicina basada en tratamientos largos y delicados con la actividad diaria de ciertos profesionales, como los carpinteros. Por todo esto, en nuestra opinión, la díaita reflejada en los escritos médicos constituía un modelo conductual aceptado y practicado por un determinado sector social. Por este motivo se ha destacado la proximidad entre la dietética médica y la gimnástica médica, disciplina esta última desarrollada también en el siglo $\mathrm{V}$ a.C. ${ }^{27}$ Ambas tenían como fundamento los beneficios del ejercicio físico sobre la salud humana y cómo se debía combinar con una adecuada alimentación.

La base del presente estudio es, precisamente, considerar la diaita como un elemento distintivo dentro y fuera de la sociedad griega ${ }^{28}$. Como se ha intentado mostrar, la dietética higiénica presentaba un conjunto de medidas y costumbres que sólo una parte de la sociedad griega podía seguir. Sin embargo, hay que advertir que ésta no fue una contribución menor a la noción de alteridad en la Grecia clásica, contribución a la que se deben sumar la introducción de estas ideas entre ciertas capas sociales y la consecuente incorporación de una parte del conocimiento médico a la educación (paideía)

${ }^{27}$ La gimnástica médica aparece asociada al sofista Pródico según Galeno, De Virt. Physic. y Cicerón, De Orat. 32.128 o a Heródico de Selimbria según Platón R. 406 a. Véase Martínez Conesa 2006: 592.

${ }^{28}$ Es relevante puntualizar que algunos escritos médicos reflejan este sentido del término díaita y otros lo circunscriben al ámbito de la alimentación (al régimen) es parte de la heterogeneidad de ideas presente en la colección hipocrática. Al respecto, J. Jouanna ha realizado una importante contribución sobre este tema donde concluye que la utilización del término díaita, como elemento colectivo definitorio, depende del contexto y es una responsabilidad compartida entre la medicina y otros géneros (Jouanna 2008). 
griega $^{29}$. En su momento Werner Jaeger apreció con claridad la difusión de los conocimientos médicos, en especial los higiénicos, al calor de una sofística que puso el acento en la educación ${ }^{30}$. Por así decirlo, los sofistas servían como eje de transmisión entre el conocimiento generado por los intelectuales y la sociedad, que recibía dicho caudal a través de la educación. En este sentido, está muy bien estudiada la estrecha relación entre la sofística y la medicina clásica, e incluso se especula con la posibilidad de que varios tratados de la colección hipocrática fueran escritos por sofistas, notablemente Sobre los flatos y Sobre la ciencia médica ${ }^{31}$. De esta forma, la medicina procuró ganarse un espacio en la vida cotidiana de la sociedad griega, especialmente entre la más acomodada. Volvamos de nuevo sobre los escritos médicos para contrastarlo, pues dice el autor de Sobre las afecciones $(=\text { Aff. })^{32}$ :

Es preciso que el hombre inteligente, dándose cuenta de que la cosa merecedora de más importancia para las personas es la salud, sepa por su propio juicio prestarse a sí mismo ayuda en las enfermedades, y sepa también diagnosticar lo que los médicos le dicen y administrar sobre su cuerpo, y sepa cada una de estas cosas en la medida que es natural a un profano.

Aff. $1^{33}$

La recomendación anterior enlaza con el objetivo que mostraba el autor de Sobre la dieta (Vict. 68) donde se recogen datos para que la mayoría tenga nociones útiles sobre medicina. En otras palabras, hay voluntad de educar a la sociedad griega en esta materia e intención por parte de los griegos de recibir conocimientos médicos ${ }^{34}$. Desde luego las evidencias de esta permeabilidad de ideas no se reducen a estos dos pasajes ni se circunscribe a la literatura médica, tenemos el caso del médico Erixímaco en el Banquete de Platón (P1. Smp. 185d-188e). La situación es bien conocida: durante un banquete el filósofo plantea una discusión sobre el amor como tema central en la que intervienen distintos intelectuales. En un momento dado de la velada, el médico Erixímaco toma la palabra y diserta sobre Eros desde el punto de vista de su arte. Este episodio se ha estudiado mucho, destacando principalmente

${ }^{29}$ No desmerecemos en este proceso la bien estudiada relación entre retórica y medicina (Jouanna 2012b) y la circulación de los médicos por las distintas ciudades quienes, a la sazón, realizaban una exposición oral para demostrar sus conocimientos (Xen. Mem. 4.2.5).

${ }^{30} \mathrm{El}$ planteamiento de Jaeger no adolece de cierta exageración en el alcance ético de la medicina (Jaeger 2012: 783).

${ }^{31}$ Escrito el primero entre finales del siglo V o principios del IV a.C. (López-Férez 1988: 27) y el segundo alrededor del último cuarto del V a.C. (Jouanna 1988: 190-191). Se trata en general de una cuestión muy estudiada por ello remito a Jouanna 1999: 80-85, con más casos.

32 Escrito quizás a principios del s. IV a.C.; véase Lucas 1997a: 129-131.

${ }^{33}$ Traducción de Lucas $1997 \mathrm{~b}$.

${ }^{34}$ También con la intención de prestigiar la medicina griega Pérez Cañizares 2012: 92. 
la pedantería del médico y la defensa a ultranza de la medicina pero, para lo que aquí nos atañe, la presencia de Erixímaco en una reunión de este tipo es un claro ejemplo de la ósmosis de los conocimientos médicos hacia la alta sociedad griega ${ }^{35}$. Si avanzamos cronológicamente tenemos el testimonio de Aristóteles, quien defiende que hay tres tipos de médico: el practicante (demiurgo), el que dirige un tratamiento y el instruido en el arte (Pol. 1282a). En efecto, el último caso hace referencia a los individuos cultos que tienen conocimientos en medicina pero no la practican ${ }^{36}$. Volviendo a la primera mitad del IV a.C., es necesario resaltar el apunte que Jenofonte realiza en Recuerdos de Sócrates mediante el caso concreto de Eutidemo, coleccionista de obras de los sabios de su época, entre las que figuraban escritos médicos (Xen. Mem. 4. 2. 8) ${ }^{37}$. Los ejemplos propuestos indican que la medicina se convirtió en un elemento importante de la educación griega como parte de una cultura general, filtrando sus nociones sobre la phýsis humana, la dietética o la influencia de la climatología en el ser humano a una sociedad que las aplicará en las más diversas circunstancias.

\section{II}

A continuación, nuestro propósito se centra en medir la influencia de las ideas y modelos médicos de la sección anterior en la Ciropedia de Jenofonte ${ }^{38}$. La modélica educación de Ciro no siempre ha despertado el interés de la crítica moderna, si bien en la actualidad se ha retomado su estudio ${ }^{39}$. La lectura de Ciropedia sugiere una suma de estilos y temas, una variedad de géneros literarios, incluso con rasgos de novela ${ }^{40}$; pero en ella también se traslucen los rasgos principales del pensamiento de Jenofonte ${ }^{41}$. La obra tiene como protagonista a Ciro I, fundador del imperio persa, tomado como paradigma de hombre virtuoso en función de tres parámetros: genealogía,

${ }^{35}$ Amplíese el tema de Erixímaco en el clásico de Edelstein 1987b y en Lara Nava 2004.

${ }^{36}$ Según Plutarco, Aristóteles será el responsable de la afición de Alejandro Magno por la medicina, parte indispensable de la formación de todo hombre culto (Plu. Alex. 8).

${ }^{37}$ Estos y otros casos se discuten también en Jaeger 2012: 795 ss.

${ }^{38}$ Obra de compleja datación, la crítica moderna plantea grandes discrepancias que sitúan un arco cronológico comprendido entre el 382 y el 360 a.C. (Bizos 1972: xlvi-xlvii). Por otro lado, en trabajos previos aislé ciertas nociones médicas como díaita y dýnamis en la Anábasis o algunas teorías genésicas en República de los lacedemonios; Sierra 2013a y 2013b, respectivamente. En este campo un excelente referente es la obra de Rosalind Thomas (Thomas 2000) sobre la influencia de ciertas nociones médicas en Heródoto, y la síntesis de Federico Borca en relación con el determinismo climático y la etnografía en la literatura antigua (Borca 2003). Por descontado hay otras aproximaciones loables que no es necesario recoger en estos momentos.

${ }^{39}$ Véase la síntesis acerca de la recepción historiográfica de Ciropedia en Due 1989: 9-15.

${ }^{40}$ En definitiva es una obra de corte didáctico sobre una gran variedad de temas: moral, educación, política, arte militar (Bizos 1972: v; Vela-Tejada 1998: 61-62).

${ }^{41}$ Bizos 1972: xlii-xliii. 
cualidades naturales para el mando y educación (Cyr. 1.1.6) (2) $^{4}$ Habría que prestar atención a las cualidades naturales que, según Jenofonte, constituyen el punto de partida para alcanzar la excelencia humana. Según Ciropedia, la phýsis de un buen gobernante es única, distinta al resto de sus congéneres, la naturaleza de Ciro aventuraba un futuro excelente pues aventajaba a todos sus compañeros (Cyr. 1.3). Por así decirlo, Ciro partía con ventaja, pero no era suficiente para alcanzar el objetivo de la perfección humana, sino que para ello necesitaba una educación acorde. La vida ejemplar, la correcta y virtuosa educación son temas socráticos recurrentes en Jenofonte y Ciropedia es su tratado más extenso sobre este asunto ${ }^{43}$. En otro lugar Jenofonte evidencia de forma explícita esta relación entre naturaleza y educación, concretamente en un interesante pasaje donde Sócrates razona sobre las cualidades naturales en el ser humano:

Creo, dijo, que lo mismo que un cuerpo nace más robusto que otro para soportar las penalidades, así, también un alma es por naturaleza más fuerte que otra frente a los peligros, pues veo que hay personas criadas en las mismas leyes y costumbres y son muy diferentes en materia de intrepidez. Pienso, sin embargo, que toda naturaleza puede acrecentar su valor con el aprendizaje y el ejercicio.

Xen. Mem. 3. $9.2^{44}$

Destaco dos ideas relevantes en conexión con el anterior capítulo: 1) la naturaleza humana no es homogénea, y 2) desde el exterior puede mejorarse (o degradarse) la misma según las costumbres adoptadas. Así, para demostrar las diferencias entre seres humanos, el ateniense fija los elementos externos que condicionan la vida, los usos y costumbres, y observa distintas naturalezas para terminar concluyendo que los seres humanos no son iguales. Continuando el argumento, la phýsis es una cualidad innata por lo que el margen de mejora humana debe situarse en los factores externos, adquiridos mediante una educación que fomente unos adecuados usos y costumbres (una correcta diaita ${ }^{45}$. Por tanto, Jenofonte plantea la definición de un modelo de perfección humana que depende de factores innatos (phýsis) y de elementos adquiridos en vida.

${ }^{42}$ Son las tres cualidades que configuran al modélico líder: gené, phýsis y paideía; Vela Tejada 1998: 52 .

${ }^{43}$ Véase O'connor 2011.

${ }^{44}$ Traducción de Zaragoza 1993.

${ }^{45}$ En República de los lacedemonios Jenofonte se adelanta al nacimiento porque quiere salvar este problema, desarrollando ideas genésicas que induzcan una determinada phýsis, una mejor naturaleza, que parte de la selección matrimonial (Sierra 2013b). 
Cómo llegar a un estado de virtud perfecto y conservarlo es una de las ideas más recurrentes y obsesivas en la obra de Jenofonte ${ }^{46}$. En Ciropedia la cuestión parte, como mínimo, de un paradigma ¿cómo consiguieron los persas dominar tantos pueblos? ¿De qué virtudes se valieron? Este punto de partida contrastaba con la idea de un imperio persa en declive, especialmente a nivel moral y militar ${ }^{47}$. El propio Jenofonte desarrolla este punto en Anábasis donde contrapone la virtuosa Persia, encarnada en Ciro el joven, frente a la decadencia personificada en su hermano Artajerjes II. En Ciropedia incide nuevamente sobre el modelo virtuoso persa desde su raíz a través de la idealizada vida de Ciro ${ }^{48}$.

Según Jenofonte, la clave del poder persa en época de Ciro I radicaba en una correcta y perfeccionada educación, considerada como una cuestión de estado e inculcada desde la infancia (Cyr. 1. 2. 2) ${ }^{49}$. La educación persa no sólo abarca los aspectos morales o la adquisición de conocimientos sino que implica instrucciones precisas para adquirir un buen tono físico gracias a la correcta combinación entre régimen y ejercicio físico ${ }^{50}$. Para comenzar, Jenofonte organiza la sociedad persa, atendiendo a la edad, y no a criterios plutocráticos o de otra clase, a partir de una división biológica. Comienza por los niños diciendo que van a la escuela para aprender valores como la justicia, la templanza o el compañerismo, aunque puntualiza lo siguiente:

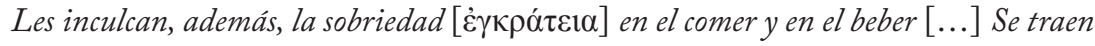
de casa el pan, como alimento básico, y berro, como companaje, y para beber, por si alguno tiene sed, un tazón para extraer agua del río.

Xen. Cyr. 1.2. $8^{51}$

El autocontrol ( $\dot{\varepsilon} \gamma \kappa \rho \alpha ́ \tau \varepsilon 1 \alpha)$ es un elemento clave en el razonamiento dietético de Jenofonte, en la idea de que la alimentación no tiene que ver con el placer de los sentidos ni con la saciedad sino con la medida y tipo exacto de

${ }^{46} \mathrm{El}$ término griego para designar virtud (aretê) posee un amplio campo semántico que puede referirse al coraje (militar, por ejemplo), a la nobleza de ánimo o la sabiduría; normalmente este concepto se vincula a las virtudes masculinas andreia, véase al respecto el análisis de Bassi 2003. Como indica M. Tamiolaki, Jenofonte utiliza normalmente el término en dos contextos: en relación a la virtud política/militar y en sentido moral (Tamiolaki 2012: 565). También coincido con esta autora en señalar que Sócrates es el culmen del modelo de virtud humana en Jenofonte (Tamiolaki 2012: 563).

${ }^{47}$ Tema muy trabajado y bien definido, véase Lenfant 2001: 408-409 y Gray 2011: 254-255.

${ }^{48}$ O'connor 2011: 50.

${ }^{49}$ En este punto República de los lacedemonios y Ciropedia presentan fuertes paralelismos; véase Tuplin 1994: 127 contra Hirsch 1997: 87.

${ }^{50}$ Entiendo la educación persa que describe Jenofonte como un modelo dirigido a un público heleno y no vinculado necesariamente a la realidad de las costumbres persas (Bizos 1972: xii). De igual manera sucede con el relato histórico y político; v. Due 1989: 38 ss.

${ }_{51}$ Seguimos la traducción de Vegas 2000. 
alimento $^{52}$. Los niños debían adquirir conocimientos en medicina, en especial acerca de las cualidades de los alimentos y las plantas, con la finalidad de conocer los productos que más benefician al ser humano, y los más dañinos (Cyr. 8. 8.13). Cada edad conlleva un régimen que se adapta a las costumbres, responsabilidades y actividad física. Superados los dieciséis años, los valores marciales ganan terreno, y es frecuente la participación en cacerías y el ejercicio en armas, simulando situaciones de guerra. La alimentación debe adaptarse a esta actividad, y los efebos han de llevar un almuerzo compuesto también de cereales y berros, pero más copioso que el de los niños y, además, se les conmina a comer de lo que han cazado (Cyr. 1. 2.11). Pasados diez años, entran en la edad adulta y las responsabilidades aumentan, formando parte activa del ejército hasta los cincuenta años. El régimen que siguen los adultos está caracterizado por el equilibrio:

Todavia en la actualidad quedan testimonios de que su régimen alimenticio es equilibrado y de que hacen bien la digestión, pues todavía en la actualidad es vergonzoso para los persas escupir, sonarse o no retener ventosidades en público, y es vergonzoso dejarse ver yendo a algún lugar a orinar o a hacer otra cosa por el estilo; y no podrian evitarlo, si no practicaran un régimen alimenticio equilibrado ni consumieran humores con trabajos pesados, de suerte que los eliminan por otros conductos.

Xen. Cyr. 1.2.16

No cabe duda de que este pasaje, a primera vista escatológico, guarda una estrecha relación con los principios médicos descritos en el apartado anterior. E1 alimento no es cantidad o placer, es equilibrio y sobriedad, pero todo en armonía con cada naturaleza humana. La phýsis y la díaita están vinculadas a la alimentación pues el régimen responde a la edad y las tareas desarrolladas. Asimismo, la evacuación de fluidos está en estrecha relación con el equilibrio natural humano, es decir, se eliminan líquidos para compensar un desequilibrio interior. Esto último es muy interesante, dado que Jenofonte identifica los signos externos (sèmeion) para interpretar el interior del cuerpo humano, lo cual es un rasgo característico de la medicina pragmática ${ }^{53}$. En este sentido, el trabajo físico ayuda y corrige los excesos de la dieta en un planteamiento análogo al desarrollado por la dietética médica. Se define así una modélica díaita basada en la moderación alimenticia y los ejercicios físicos de inspiración bélica.

Toda vez que Jenofonte introduce el modelo persa gradualmente, presenta el contra-modelo protagonizado por el pueblo de los medos. Por ejemplo, la

${ }^{52}$ La cuestión del autocontrol queda bien identificada en Due 1989: 95, quien no parece percibir la relación entre esta idea y la dietética higiénica de la época.

${ }^{53}$ Jouanna 1999: 249. 
primera vez que Ciro se sentó en la mesa con su abuelo, el medo Astiages, aflora en la narración el lujo y la abundancia de manjares (Cyr. 1. 3.4). A través del alimento, su condimento y cantidad se plantea una diferencia de modelos antagónicos donde los medos representan todo aquello nocivo y contaminante; una tendencia hacia la opulencia, la vida muelle y la desmesura (býbris). Ante tanta abundancia, el pequeño Ciro replica a su abuelo que en Persia se conforman con menos, son comedidos, y el pan y la carne bastan para saciar el hambre. Tan marcada era la personalidad de Ciro al respecto que, cuando su abuelo lo convence para quedarse en Media, le promete que podrá mantener la díaita propia de los persas: Después, respecto a la comida, podrás seguir la vía que quieras para conseguir la dieta que te parezca equilibrada (Cyr. 1.3.13). Esta anécdota sirve a Jenofonte para resaltar la importancia del equilibrio en la definición de un modelo de virtud humana y Ciro, pese a su corta edad, mantuvo las correctas costumbres persas, no se corrompió por la desmesura meda ${ }^{54}$. Progresivamente surge la idea de contaminación por contacto, es decir, las buenas costumbres corren el riesgo de olvidarse pues requieren de buena disposición de ánimo y esfuerzo ${ }^{55}$. Por ejemplo, años después, cuando Ciro regresó a Persia, sus compañeros pensaban que las costumbres medas le habrían corrompido pero al verle comer al estilo persa salieron de dudas y volvieron a respetarle (Cyr. 1.5). Siguiendo esta razón, Jenofonte destaca que los enemigos de Persia valoraban en sus gobernantes la opulencia, la glotonería y la vida ociosa, características todas ellas de sociedades decadentes (Cyr. 1.6.8).

Con estas virtudes como bandera, Ciro se convirtió rápidamente en un gran líder militar por sus conocimientos, educación y en un modelo a seguir para la tropa. Cuando llega a la edad adulta, la Ciropedia entra en una faceta diferente y gira hacia un tratado militar. Por ejemplo, cuando el medo Ciaxares recibe la noticia de que será atacado por sus antiguos aliados, Ciro acude en su auxilio y mantiene un intercambio de impresiones con su padre (Cambises) mientras lo acompaña hasta la frontera entre Persia y Media (Cyr. 1. 6. 1). E1 diálogo resulta un recurso literario para introducir una suerte de manual sobre gestión militar centrado principalmente en cuestiones logísticas y de gobierno ${ }^{56}$ (Cyr. 1.6.2-44). Resultan interesantes para el tema que nos ocupa algunas precisiones higiénicas que conectan con el ideario

${ }^{54}$ La madre de Ciro, hija de Astiages, no se fía de la bondad de las costumbres medas (Cyr. $1.3 .16 \mathrm{ss})$.

${ }^{55}$ Idénticamente queda reflejado en Anábasis (3.2.25-26) sobre la presumible contaminación de las costumbres griegas al permanecer largo tiempo en territorio persa (Sierra 2013a: 472).

${ }^{56}$ Coincidimos con Gray 2011: 265 al señalar que el diálogo entre padre e hijo no sirve a este último para aprender sino para refrescar conocimientos. El tema central es la dificultad de liderar un ejército. 
médico de la época. Éstas abarcan una parte importante de la digresión (Cyr. 1. 6.15-19), debiendo el general ocuparse de que la tropa tenga los víveres necesarios y de que no haya enfermos en el ejército. La prevención es clave según Cambises, el médico actúa cuando la enfermedad se ha manifestado, y por ello aconseja a Ciro que los soldados adopten las mismas medidas y costumbres que él, éstas son:

En primer lugar, por Zeus, intento no quedar nunca demasiado lleno en la comida, porque resulta pesado. En segundo lugar, hago ejercicio para digerir lo que haya ingerido; pues me parece que así la salud se mantiene mejor y aumenta el vigor.

Cyr. 1.6.17

El ejercicio físico debe ir en consonancia con la ingesta de alimentos, principio básico de la dietética higiénica que reproduce Jenofonte como fundamento para mantener la salud ${ }^{57}$. Resulta notable que en el relato es Ciro el poseedor de la educación y los conocimientos higiénicos adecuados mientras que los soldados de inferior rango deben ser enseñados. A continuación padre e hijo dialogan sobre la mejor manera de fomentar esta conducta entre los soldados, llegando a la conclusión de que el ejército debe estar bien entrenado, de la siguiente manera:

Ciro se ocupaba también de que nunca entraran [los soldados] a desaynnar o cenar sin haber sudado previamente: les provocaba el sudor sacándolos de caza, o ideaba un tipo de juegos que se lo fuera a producir, o incluso, si ocurría que habia alguna otra labor que realizar, llevaba de tal modo la acción, que ellos no volvieran sin sudor. Pues consideraba que haber sudado era conveniente para comer con satisfacción, para mantenerse sanos y para adquirir la capacidad de soportar fatigas [...]

Cyr. 2.1.29

Si en el primer pasaje Ciro expone sus hábitos higiénicos (alimentación y ejercicios), en este segundo lo vemos convertido en el dietista de su tropa $^{58}$. En el fondo, Jenofonte sugiere que el caudillo militar debe poseer conocimientos médicos, sobre todo higiénicos, para mantener operativo a su ejército. Pero todas estas consideraciones atañen a los persas porque sus aliados, en especial los medos, seguían otras costumbres. En cierto sentido, en Ciropedia no se dejan de comparar modelos educativos y humanos bien sea entre persas y el resto de pueblos asiáticos o, indirectamente, entre la

${ }^{57}$ El ejemplo de Ciro evoca otro modelo, el de Iscómaco (Xen. Oec. 11. 18-20) que mantenía un correcto equilibrio entre actividad física y alimentación. El hábito de Ciro se repite en otros lugares de Ciropedia (8.1.38).

${ }^{58}$ Más adelante procurará lo mismo al organizar su palacio (Cyr. 8. 2.24). 
supuesta educación persa de Jenofonte y la griega. La alimentación se convierte en el signo inequívoco de la educación y el carácter de las personas; así, los medos siempre se muestran glotones y ávidos de lujo, en tanto que los persas practican el autocontrol y aman la austeridad. Un ejemplo de ello queda recogido tras la victoria de medos y persas sobre los asirios: los primeros se entregaban al saqueo y pasaron la noche banqueteando mientras los persas se preocupaban de la vigilancia y defensa del campamento ${ }^{59}$ (Cyr. 4. 5). Es más, en los momentos de carestía Ciro se mostró todavía más celoso de la salud de los soldados. Así, ante la previsión de una carencia de vino, el caudillo recomienda acostumbrarse lo antes posible a beber agua para que el cambio repentino de dieta no produzca enfermedades entre la tropa (Cyr. 6. 2.26ss). Esta es una teoría propia de la dietética médica de la época de Jenofonte y que podemos seguir en Vict. 68 donde se especifica que los cambios súbitos de dieta conllevan desequilibrios internos ${ }^{60}$. La cuestión es un topos en Jenofonte pues en Anábasis la expedición griega debía adaptarse continuamente a la variación de la dieta, la falta de alimentos o a la ingesta de productos desconocidos. Asimismo, en Lac. 2. 5, los jóvenes espartanos están educados en la carestía, a fin de que puedan adaptarse a todo tipo de dieta en caso necesario ${ }^{61}$.

No quisiéramos pasar a la valoración final sin comentar algún detalle aislado que conecta la Ciropedia con una noción planteada en el primer apartado: la teoría climática, apuntada en la citada conversación entre Ciro y su padre. Entre las recomendaciones higiénicas se introduce la idea de buscar el lugar más salubre para acampar (Cyr.1.6.16); pese a que avanzada la obra encontramos un apunte similar, (Cyr. 6.1.23) la conexión con Aër parecería remota de no ser por lo siguiente:

[...] los limites de estas regiones [de su imperio] son inhabitables unos por el calor, otros por el frío, otros por el agua y otros por la sequedad. Yél, tras fijar su residencia en medio de éstos, hacia la época de invierno pasaba en Babilonia siete meses; pues ésta es la región más cálida; hacia la primavera tres meses en Susa; en el rigor estival, dos meses

${ }^{59}$ Otro ejemplo podría ser la sorpresa que muestra Gobrias al sentarse a la mesa con los persas y observar la sencillez de la comida y la ausencia de avidez en los comensales (Cyr. 5. 2 . 14-24). Hay ejemplos por doquier en Ciropedia. Combatir la glotonería y el lujo culinario es otro de los temas recurrentes de Jenofonte como indica Soares 2012: 39 al analizar un interesante pasaje Mem. 3.14- 5-6.

${ }^{60}$ Esta es una idea que no comparten todos los autores de la colección hipocrática. En Acut. 27 se dice que los pequeños cambios de hábitos (también alimenticios) son beneficiosos. Siguiendo a Camassa 2006: 21, la tendencia general en el pensamiento médico es la contraria tal y como lo recoge Jenofonte.

${ }^{61} \mathrm{El}$ tema queda recogido en Sierra 2013a: 471-476 para la Anábasis y en Sierra 2013b: 59-60 para Lac., ambos con bibliografía. Este dato confirma la confluencia de las tres obras sobre este tema y la conexión con la dietética médica de la época. 
en Ecbatana, y dicen que, haciendo asi, Ciro vivía siempre en un clima primaveral y templadamente fresco.

No resulta gratuito que Jenofonte destaque la cuestión de la variación del clima cuando acaba de presentar resumidamente la magnitud de las conquistas y el imperio de Ciro. La idea según la cual el clima influye en la salud humana, en la phýsis, presenta una conexión evidente con la medicina, aunque en lo concreto hay diferencias. Según Aër. 12, los climas extremos producen seres humanos vigorosos y aguerridos mientras que los climas templados generan individuos pusilánimes ${ }^{62}$. En cambio, Jenofonte no destaca esta medida como catalizador del coraje de Ciro sino más bien como una previsión de vejez, una medida adoptada en tiempos de $\mathrm{paz}^{63}$. A pesar de que ambas ideas no coinciden en lo particular sí lo hacen en lo general al proponer que el clima influye en la salud de las personas.

\section{III}

A modo de conclusión, la Ciropedia se alinea con ciertas ideas médicas de su época, en especial con aquellas relacionadas con la medicina higiénica. No hemos resaltado una relación concreta entre Ciropedia y algún escrito médico debido a la heterogeneidad de ideas en la colección hipocrática, si bien entendemos que existe una correlación con los principios generales mostrados en el primer apartado. Los conceptos de phýsis, dýnamis y díaita no eran ajenos a Jenofonte aunque sus inquietudes tomen caminos distintos a la medicina. Claramente la Ciropedia es, entre otras muchas cosas, un tratado de cómo alcanzar y mantener un estado de excelencia a nivel individual y colectivo. Si atendemos al célebre y controvertido epílogo (Cyr. 8.8), podría decirse incluso que versa sobre el auge, cénit y decadencia del imperio persa a través de la novelada vida de Ciro ${ }^{64}$. Al respecto, Platón ( $\left.L g .694 a-696 b\right)$

${ }^{62}$ Idéntica información en Heródoto (9.122. 2) y Aristóteles Pol. 1327b 23-33; v. Jouanna 1996: 9 .

${ }^{63}$ Esta es la relación más directa con la teoría del determinismo climático en Ciropedia. No obstante, Johnson 2005: 194 incluye un ejemplo donde se explica que los persas provenían de un territorio agreste y pobre (Cyr. 7.5.67), lo cual rubrica Arriano (An. 5. 4. 5) y el autor enlaza ambos datos y sugiere que contravienen las disposiciones de $A \ddot{e}$. 24; donde se especifica que los asiáticos gozaban de un clima bueno y monótono, que producía hombres pusilánimes. Revisando ambos pasajes, el contexto del primero hace énfasis en la pobreza de los persas, que condiciona la decisión de Ciro de trasladarlos a palacio; mientras que el pasaje de Arriano apunta que los persas de época de Ciro eran pobres, habitaban un territorio áspero y su educación era similar a la espartana. Desde nuestro punto de vista, no hay elementos suficientes para conectar ambos pasajes con Aires, aguas y lugares, es decir, ni Jenofonte ni Arriano mencionan que el clima persa influyó en las cualidades físicas y psíquicas de los persas.

${ }^{64}$ Debido a las dudas sobre la autoría y la problemática que encierra el epílogo, no se ha 
defiende que fue el propio Ciro el causante de la decadencia persa al dejar que sus hijos fueran educados por las mujeres. Como indica David M. Johnson, este pasaje se ha interpretado como una respuesta a la Ciropedia de Jenofonte, dado que achaca la decadencia de las costumbres persas al propio Ciro y no a sus sucesores ${ }^{65}$. Pudiera ser que Platón conociera el contenido de Ciropedia y que rompiera de este modo con el modelo de virtud que Jenofonte teje alrededor de Ciro; puesto que el objetivo principal de la obra no es tanto enaltecer al fundador del imperio aqueménida, sino mostrar el camino hacia la perfección humana. Por tanto Ciro y los persas son una excusa para definir un modelo que se repite en otras obras del historiador.

Como reflexión general, la Ciropedia muestra la conexión con las siguientes ideas: la naturaleza no es igual en todos los seres humanos, al tiempo que los factores externos pueden modificarla para bien o para mal. En este sentido, Ciro nació con una naturaleza superior a las demás, y, mediante una buena educación, adquirió los hábitos para alcanzar la excelencia.

En cuanto a la alimentación, cabe decir que el ateniense muestra a lo largo de la obra su comprensión de la dietética médica. Los alimentos tienen unas cualidades (dynámeis) y su aprovechamiento es diferente, de acuerdo con las circunstancias del individuo: edad, sexo, actividad física, etc. Acentúa sobre todo la noción del equilibrio dietético como fuente de salud, la glotonería es un vicio que degenera en molicie; el alimento no sirve al placer sino al cuerpo y por ello no son necesarios los condimentos. Precisamente estas prescripciones propias de la medicina higiénica son las que más abundan en Ciropedia y ello es congruente con la circulación de ideas médicas en la Grecia clásica. No obstante, definiendo este modelo de virtud es donde se destilan cuestiones que tienen relación directa con la alteridad. Aquellos que se mantenían con una comida al día, a base de alimentos sencillos pero adecuados, realizaban ejercicio para preservar el vigor, al tiempo que eran moderados en la bebida y los placeres... Todos estos formaban parte de un colectivo virtuoso que adaptaba su vida a unas directrices, a una díaita, y ello se exteriorizaba mediante una complexión robusta, buena talla y tono muscular ${ }^{66}$. Frente a éstos estaban los que llevaban una vida muelle, como los medos, abocada a los placeres y que se exteriorizaba en una falta de vigor e ímpetu en las acciones llevadas a cabo. Por consiguiente, Ciropedia pretende mostrar que con leyes adecuadas

incluido en el cuerpo central del análisis. Sobre esta cuestión, su trayectoria historiográfica y su relación con el epílogo de República de los lacedemonios y Recuerdos de Sócrates véase Meulder 1989; Due 1989: 1616-22; Tuplin 1994: 134-141 y Gray 2011: 256 n15.

${ }^{65}$ Johnson 2005: 180-181.

${ }^{66}$ Resulta más explícito todavía en Lac. 5. 8; Ages. 1.28 y HG 3. 4.19; v. Sierra 2013b: 61-62. 
hasta las naturalezas más viles pueden ser buenas, y al revés, que las mejores naturalezas pueden echarse a perder ${ }^{67}$.

En síntesis, el vaciado de datos realizado en Ciropedia confirma que en la construcción del citado modelo de virtud humana, Jenofonte utilizó principios e ideas propios de la medicina de su época. Todo ello guarda cierto vínculo con otras obras del ateniense como Anábasis o República de los lacedemonios, lo cual nos lleva a pensar en un modelo global tendente a definir los caminos por los que el ser humano alcanza la perfección espiritual y física. Con este modelo Jenofonte quiso explicar realidades históricas, como la decadencia de Esparta o Persia, que se apartaron de sus ancestrales normas y, ante esto, no hay naturaleza que se sobreponga.

\section{Bibliografía}

Bartos, H. (2015), Philosophy and Dietetics in the Hippocratic On Regimen. A Delicate Balance of Health. Leiden.

Bassi, K. (2003), "The Semantics of Manliness in Ancient Greece", in R. M. Rosen; I. Sluiter (eds.), Andreia. Studies in Manliness and Courage in Classical Antiquity. Leiden/Boston, 25-58.

Bizos, M. (1972), “Notice”, in Xénophon. Cyropédie. París, v-lx.

Borca, F. (2003), Luoghi, corpi, costumi: determinismo ambientale ed etnografia antica. Roma.

Camassa, G. (2006), "L'idea del mutamento nel Corpus Hippocraticum”, in A. Marcone (ed.), Medicina e società nel mondo antico. Atti del convegno di Udine (4-5 ottobre 2005). Firenze, 16-25.

Craik, E. (2006), Two Hippocratic Treatises. 'On Sight' and 'On Anatomy'. Leiden.

Due, B. (1989), The Cyropaedia. Xenophon's Aim and Methods. Aarhus.

Edelstein, L. (1987a), “The Dietetics of Antiquity”, in O. Temkin; L. Temkin (eds.), Ancient Medicine. Selected papers of Ludwig Edelstein. Baltimore, 303-316.

Edelstein, L. (1987b), "The Rôle of Eryximachusin Plato's Symposium”, in O. Temkin; L. Temkin (eds.), Ancient Medicine. Selected papers of Ludwig Edelstein. Baltimore, 153-171.

García Gual, C. (2000), "Sobre la dieta”, in Tratados hipocráticos. Madrid.

Gray, V. J. (2011), Xenophon's Mirror of Princes. Reading the Reflections. New York.

Hirsch, S. W. (1997, 2a ed.), Friendship of the Barbarians. Xenophon and the Persian Empire. Hanover.

Jaeger, W. (2012,12a ed.), Paideia: los ideales de la cultura griega. México.

${ }^{67}$ Véase por ejemplo el caso de Feraulas, quien desde una condición muy humilde, pero con buenas normas y educación, no era inferior a los compañeros de Ciro (Cyr. 8.35 ss.). 
Johnson, D. M. (2005), "Persians as Centaurs in Xenophon's 'Cyropaedia”, TAPhA 135(1): 177-207.

Joly, R. (2003), "Introduction”, in Hippocrate. Du Regime. Paris, 19-117.

Jouanna, J. (1988), “Notice”, in Hippocrate. Des Vents. De Art. París (CUF), 167-223.

Jouanna, J. (1996), “Notice”, in Hippocrate. Airs, Eaux, Lieux. Paris(CUF), 7-184.

Jouanna, J. (1999), Hippocrates. Baltimore.

Jouanna, J. (2008), "Réflexions sur le régime des peuples dans la Grèce classique (Hérodote I, 133; Hippocrate Ancienne Médecine, c. 5 ; Thucydides I, 6) et sur le sens des mots de la famille de Diaita", REG 121 (1): 17-42.

Jouanna, J. (2012a), "Dietetics in Hippocratic Medicine", in Greek Medicine. From Hippocrates to Galen. Selected papers. Leiden, 137-153.

Jouanna,J. (2012b), "Rhetoric and Medicine in the Hippocratic Corpus. A Contribution to the History of Rhetoric in the Fifth Century", in Greek Medicine. From Hippocrates to Galen. Selected papers, Leiden, 39-53.

Jouanna, J. (2012c), "Water, Health and Disease”, in Greek Medicine. From Hippocrates to Galen. Selected papers. Leiden, 155-172.

Laín Entralgo, P. (1970), La medicina hipocrática. Madrid.

Laín Entralgo, P. (1982), El Diagnóstico Médico. Historia y Teoría. Barcelona.

Lara Nava, M. D. (2004), "El prestigio del médico hipocrático”, $C F C(g)$ 14: 45-58.

Lenfant, D. (2001), “La 'décadence’ du grand roi et les ambitions de Cyrus le Jeune: aux sources perses d'un mythe occidental ?”, REG 114(2): 407-438.

Lloyd, G. E. R. (1991), "The Empirical Basis of Physiology of the Parva naturalia”, in Methods and Problems of Greek Science. Cambridge, 224-247.

López Férez, J. A. (1986), "Hipócrates y los escritos hipocráticos: origen de la medicina científica”, Epos 2: 157-176.

López Férez, J. A. (1988), “'Sobre los flatos' como reflejo de la sofística en Corpus bippocraticum”, CFC 21: 25-43.

López Férez, J. A. (2000), “Aires, aguas y lugares”, in Tratados hipocráticos. Madrid.

Lucas, J. M. (1997a), “Introducción”, in Tratados hipocráticos III. Madrid, 119-140.

Lucas, J. M. (1997b), Sobre las afecciones. Tratados hipocráticos. Madrid.

Martínez Conesa, J. A. (2006), "La gimnástica médica y el tratado hipocrático Sobre la dieta”, in E. Calderón; A. Morales; M. Valverde (eds.), Koinòs lógos. Homenaje al profesor José García López. Murcia, 589-594.

Meulder, M. (1989), “La date et la cohérence de la République des Lacédémoniens de Xénophon”, $A C 58: 71-87$.

Nutton, V. (2004), Ancient Medicine. London.

O'connor, D. K. (2011), “Xenophon and the Enviable Life of Socrates”, in D. R. Morrison (ed.), The Cambridge Companion to Socrates. New York, 48-74.

Paiaro, D. (2012), "Relaciones de dependencia en la Atenas clásica, entre la explotación y la dominación”, Trabajos y comunicaciones 38: 153-183. 
Pérez Cañizares, P. (2010), “The importance of having medical knowledge as a layman. The Hippocratic treatise Affections in the context of the Hippocratic Corpus", in M. Horstmanshoff (ed.), Hippocrates on Medical Education. Selected papers read at the XIIth International Hippocrates Colloquium, Universiteit Leiden 24-26 August 2005. Leiden, 87-99.

Rodríguez Alfageme, I. (1997), “Introducción”, in Tratados hipocráticos III. Madrid, 237247.

Sierra, C. (2013a), "Díaita: estilo de vida y alteridad en la Anábasis de Jenofonte", Athenaeum 101(2): 463-477.

Sierra, C. (2013b), "Hipócrates y los espartanos", Quaderni di storia 77: 49-67.

Sierra, C. (2014), "La medicina como modelo de la política: algunos apuntes sobre una antigua metáfora", Aiônos: Miscellania di Studi Storici 17: 271-292.

Sierra, C. "Médico y esclavo: relaciones de dependencia en la medicina griega", in I. Arrayás; J. Cortadella; O. Olesti (eds.), Lo viejo y lo nuevo. XXXVI Coloquio del Girea. Barcelona. (en prensa).

Soares, C. (2012), “Arte culinária em Xenofonte, Platão e Aristóteles”, in C. Soares; P. Dias (coords.), Contributos para a história da alimentação na antiguidade. Coimbra, 35-47.

Smith, W. D. (2002, 2a ed.), The Hippocratic Tradition. Ithaca.

Tamiolaki, M. (2012), "Virtue and Leadership in Xenophon: Ideal Leaders or Ideal Losers?", in F. Hobden; Ch. Tuplim (eds.), Xenophon: Ethical principles and historical enquiry. Leiden/Boston, 563-590.

Thivel,A.(1990), "Flux d'humeurs et cycle de l'eau chez les Présocratiques et Hippocrate”, in P. Potter; G. Maloney; J. Desautels (eds.), La maladie et les maladies dans la Collection Hippocratique. Actes du VIe Colloque International Hippocratique (Québec, du 28 septembre au 3 octobre 1987). Québec, 277-302.

Thomas, R. (2000), Herodotus in context. Ethnography, Science and the Art of Persuasion. Cambridge.

Tuplin, ch. (1994) "Xenophon, Sparta and the Cyropaedia", in A. Powell; S. Hodkinson (eds.), The Shadow of Sparta, London, 127-181.

Vegas A. (2000), Jenofonte. Ciropedia. Madrid.

Vela Tejada, (1998), Post H. R. Breitenbach: tres décadas de estudios sobre Jenofonte (19671997). Zaragoza.

Wilkins, J. (2005), “The Social and Intellectual Context of Regimen II”, in Ph. van der Eijk (ed.), Hippocrates in Context. Papers read at the XIth International Hippocrates Colloquium. University of Nerwcastle Upon Tyne, 27-31 August 2002. Leiden, 121133.

Zaragoza J. (1993), Jenofonte. Recuerdos de Sócrates. Económico. Banquete. Apología de Sócrates. Madrid. 